\title{
Advancing the Disaster and Development Paradigm
}

\author{
Andrew E. Collins ${ }^{1}$
}

Published online: 12 December 2018

(C) The Author(s) 2018

\begin{abstract}
Consolidation of disaster and development studies as an integrated field of action research that influences policy has proved to be fundamental to global disaster risk reduction, sustainable development, climate change, and humanitarian agreements. However, challenges in achieving targets, such as those of the Sendai Framework for Disaster Risk Reduction 2015-2030 and the Sustainable Development Goals, requires further advances of the disaster and development paradigm underpinning these aspirations. This article presents perspectives that grew primarily from local action research, particularly research carried out with marginalized and highly at-risk groups of people in Southern Africa and South Asia. Analytical fronts from these findings emphasize disaster and development risk assessment opportunities that consolidate earlier ideas and extend understanding of disaster and development-related risk intervention options. These acknowledge severe shortcomings in disaster risk reduction progress while including greater use of hope as an active ingredient. This process of paradigm exploration remains fundamental to achieving disaster risk reduction, sustainable development, and associated policy objectives. The analysis presented here reiterates earlier groundings in people-centric perspectives, emphasizing social relations and systems of meaning as essential active ingredients for challenging power structures, technology, education, and human behavior. The analysis proposes some consequent thematic fronts for increased investment. These include
\end{abstract}

Andrew E. Collins

andrew.collins@northumbria.ac.uk

1 Department of Geography and Environmental Sciences / Disaster and Development Network (DDN), Northumbria University, Newcastle upon Tyne NE1 8ST, UK investing in early buildup of well-being before a disaster, better living with uncertainty, and overcoming the barriers to desired disaster and development outcomes. The article is intended to contribute to an ever-evolving paradigm of disaster and development risk that requires impetus from personal and collective values beyond calculations of disaster and development.

Keywords Disaster and development paradigm - Disaster risk reduction - Disaster risk management $\cdot$ Local action research

\section{Introduction}

The application of disaster risk management to sustainable development to achieve disaster reduction has variously formed a part of integrated disaster and development studies over decades. For this article disaster risk management is subsumed into disaster risk reduction (DRR) terminology. Disaster events impact on development possibilities, while post-disaster recovery and human resilience requires environmental, societal, and economic sustainability. It was in response to the theoretical, policy, and practice basis of this relationship that the world's first center of international postgraduate studies in combined disaster management and sustainable development was launched at Northumbria University, United Kingdom in the late 1990s. Its intake of students started in Millennium year 2000 and continues to date. The integration of this field has since progressed both in global policy and local actions. Disaster and development approaches are emphasized in transitioning from the Hyogo Framework for Action 2005-2015 (HFA) to the Sendai Framework for Disaster Risk Reduction 2015-2030 (SFDRR). The 
SFDRR (UNISDR 2015a) is recognized as a driver for achieving the Sustainable Development Goals (SDGs) (UNISDR 2016a) and is also often cross-referenced with the revision of ongoing climate change and humanitarian agreements. However, the nature of change in politics, behavior, and knowledge required for achieving the SFDRR goal and the SDGs requires more in-depth analysis and application. ${ }^{1}$ Given that progress lags behind what is required, it is timely to consider how the disaster and development paradigm might be advanced.

This article provides a comment on perspectives that persist as part of the disaster and development paradigm, guided by action research findings from Northumbria's work in this field, in order to assess how to advance the paradigm conceptually in order to further steer implementation of disaster risk reduction. This will also help to reassess what should be added by way of analytical fronts in order to bring about advances in disaster and development awareness building and improved governance of disaster risk reduction. Three thematic areas are promoted here as underpinning potential advances in applied disaster and development studies, addressing theory, policy, and practice going forward. These fronts are broadly described as: (1) build up earlier a human well-being that offsets negative risk; (2) live better with uncertainty; and (3) know the nature of barriers to more effective transitions in sustainable development and disaster risk reduction.

\section{Persistent Perspectives of Disaster and Development}

The section of the article brings to the fore perspectives on disaster and development from earlier findings alongside interpretations that can advance the paradigm and in so doing underpin a knowledge of more means to achieving effective disaster risk reduction.

\subsection{Disaster and Development as Common Sense}

Common sense reflection on disaster and development concludes that these are combined processes of change that are exemplified by a long-term propensity of humanity to demonstrate its capacity to fall unprepared into both personal and collective catastrophe, while at the same time

\footnotetext{
${ }^{1}$ Goal of the Sendai Framework for Disaster Risk Reduction 2015-2030 - "Prevent new and reduce existing disaster risk through the implementation of integrated and inclusive economic, structural, legal, social, health, cultural, educational, environmental, technological, political and institutional measures that prevent and reduce hazard exposure and vulnerability to disaster, increase preparedness for response and recovery, and thus strengthen resilience." (UNISDR 2015a, Paragraph 17, p. 12).
}

develop relative health and well-being. Combined disaster or development outcomes come and go across anthropogenic landscapes that are undergoing accelerated change. Major catastrophic events have altered trajectories of human survivability and quality of life throughout largely unquantifiable environmental, social, and economic disruptions dating from before records began. In relatively recent academic discourses addressing the precariousness of everyday human life, reducing disaster risk, and achieving more sustainable development present as common agendas (Collins 2009a, 2013). There are many overlapping ways in which the field has been formulated. For example, and by way of a few of the indicative sources, reducing disaster requires actions to address both proximate and underlying risks (Blaikie et al. 1994; Wisner et al. 2004), hazards mitigation (Tobin and Montz 1997; Godschalk et al. 1999; Smith 2001), and fundamentally imposed human vulnerability (Cannon 1994; Lewis 1999, 2014; Cutter et al. 2003; Bankhoff et al. 2004; Gaillard 2010). Though much of the field has been, and often continues to be, analyzed from a natural-hazards orientation, a significant drive has shifted the paradigm to be people centered through more socially, politically, economically, and culturally aware agendas (Hewitt 1995, 1997; Collins 2009a, b; Pelling and Dill 2010; Collins et al. 2015; Krüger et al. 2015).

Post-crisis development had been belatedly recognized within emergency relief as incomplete where it is only oriented to immediate survival; relief agencies needed to invest in recovery of development processes over time (Cuny 1983). Shifting the agenda, agencies formerly specializing in emergency relief transitioned their work to include more developmental approaches. Calls to recognize relief and development investments as essentially political processes also challenged conventional norms of humanitarian assistance of the day (De Waal 1997; Middleton and O'Keefe 1998). Other discourses further brought out the socially constructed nature of disaster and its definition relative to context (Hewitt 1995; Quarantelli 1998; Perry and Quarentelli 2005) and human rights-based imperatives in disasters (Enarson and Fordham 2011; IFRC 2007). These emphases continue to overlap with each other and get variously shared across a myriad of subsequent authorships; only a few indicative sources are provided here. The resultant knowledge base remains instrumental to a convergent lexicon within current disaster management that is now also pervasive in global policy narratives. Some further evidence of the impact on discourse is reflected in the definitional content of disaster management terminology itself (UNISDR 2016b) within which the concepts accompanying more people-centered approaches are now easier to recognize than they were under more hazards dominated approaches. 
While much progress can be identified in terms of disaster and development-based problem analyses, with some common goals being identified and getting reflected in global policy, both disaster risk reduction and sustainable development needs have yet to be resolved in most parts of the world. Something of an ideological front has been advanced, but requisite actions to bring fundamental change lag woefully behind. An urgent concern is necessarily being reemphasized in that the focus of the problem is essentially about how to better intervene in "disaster risk creation" (Lewis 2012), whether in terms of demographics, environmental sustainability, human security, or in linking disaster and conflict risk reduction (Collins 2019), among various other means. Given the critical condition in which a majority of the world's inhabitants find themselves living, it is reasserted that urgent further progress is needed and that a burgeoning field of disaster and development studies has only just begun.

Although the field lags behind demands for immediate implementation, there are empirically based studies in disaster affected locations that already have a lot to offer in terms of better understanding the nature of many of the obstructing issues and some ways forward. For example, there have been working case studies instigated through Northumbria's disaster and development field-based work that took place during this first part of the Millennium. These projects included a range of community-based disaster risk engagement activities in Mozambique, Zimbabwe, Bangladesh, and Nepal involving in each instance listening to and working with the motivations of local people, local authorities, and wider level bureaucrats to achieve impacts. The research tools and engagement processes varied depending on the identified demand for risk reduction for survivability and well-being. An infectious disease risk reduction project in Mozambique and Bangladesh involving tens of thousands of people caught up in epidemics progressed through integrating community driven infectious disease risk monitoring alongside adapted community and government led responses (Collins et al. 2006; Williams et al. 2010). A further example was borne out by a community driven natural resources risk mitigation and development project in the upper Zambezi region of Zimbabwe. This similarly enabled action research-oriented techniques and engaged legal services for entire communities to be able to know and apply their rights in the sustainable use of local resources critical to their survival in contexts of marginalization (Manyena et al. 2012, 2016). Comparative evidence based research with several communities in Nepal (Jones et al. 2013, 2014) was able to inform on barriers to safety and opportunities to progress through the varied structuring of risk governance in relation to specific social groups.
Many other examples of action-oriented research in disaster affected locations are documented by the organizations of the United Nations around the world, presented through Global Platforms and Global Assessment Reports (for example, UNISDR 2009, 2011a, b, 2013, 2015b; WHS 2016). The Northumbria projects with groups of local partners and communities in affected areas of Southern Africa and South Asia essentially found that:

- People, even in marginalized situations, can control ecological and socioeconomic risks where these are well understood. This includes risk caused by climate change, hazardous environments, poverty, and human instability.

- Community self-organization and wider good governance define resilience to disasters.

- It is possible to reduce human activities that contribute to environmental and other disaster risks without knowing everything. ${ }^{2}$

The findings from the range of specific field-based examples are essentially people centric and show that disaster risk reduction and good governance-based disaster and development actions are core drivers for progress. This should not always be considered as entirely new knowledge but rather as empirically based reaffirmations of an oftenneglected understanding of humanity. Together with the observations of many recent reflections on this field, the findings point, perhaps unsurprisingly, to disaster reduction or development progressing at the local level where it is:

- Informed-by ongoing real or perceived threats of the governed;

- People centered-being driven and motivated by disaster assessment that is multidisciplinary, integrated, and perpetually reassessed;

- Practitioner oriented-being guided by a perpetual interpretation and review process;

- Proactively engaged-including with hazards, vulnerability, and coping to facilitate resilience;

- Guided where possible by lessons learned-through evaluation before, during, and after risk reduction activities;

- Related to localized knowledge—being made relevant through grounded research;

\footnotetext{
2 These overall findings constitute a selection of key points from more than 10 Northumbria coordinated studies carried out between 2002 and 2014 funded by Economic and Social Research Council (ESRC), Department of International Development (DFID), British Council, WHO, UNICEF, UNHCR, and others. Further information is available as an Impact Case Study reported by the UK Collaborative for Development Research (UKCDR) at http://www.ukcdr.org.uk/theglobal-impact-of-uk-research/communities-against-disasters.
} 
- Invested in-where there is the political will, institutional and personal commitment to disaster reduction and sustainable development.

With better-honed evidence, principles such as these are now increasingly recognizable in global discourses such as the SFDRR. With suggested operational basics more prominent in the shifts required for policy and practice, although still underutilized, it is timely to step further into what can increase more effective engagement in this disaster and development informed DRR agenda.

\subsection{Going Deeper in Applied Disaster and Development Studies}

Despite much existing common sense in the paradigm there are clear analytical and practical challenges in the application of disaster risk management and sustainable development for disaster reduction. For example, considering that flood risk includes environmental change, human exposure, and the nature of prevention and response systems, it is necessary to address predictability/uncertainty, opportunity for precautionary actions, "natural" versus built approaches, hard and soft catchment, river and coastal management, and the methods of long-term maintenance (Collins et al. 2015). In relation to exposure factors, perception, socioeconomic enablement, information, communication, expectation, culture, age, gender, and other forms of social differentiation are more relevant (Collins et al. 2015). In relation to the same flood events, prevention and response systems raise challenges of political will, market forces, capacity, connectedness with proximate and underlying causes, learning cycles, adaptive capacity, role management, centralization/decentralization, hard/soft catchment management (upstream/downstream), maintenance, public and private responsibilities, and the roles of insurance (Collins et al. 2015).

Moving beyond flood risk, with respect to multi-hazard and risk environments - and noting that actions for disaster risk reduction lie in structural contexts and political will, human behavior and education, science and technologyconsideration should also be directed at multileveled (or enveloping) societal relations and systems of meaning (Fig. 1, I and II). Case studies reporting the implementation of disaster risk reduction actions, such as those referred to in the previous subsection, variously refer to or imply this disaster and development contextualization. Social relations aspects involve roles in disaster and development working relationships and forms of domination in the public, private, and community sectors, and in the development of the subject area. These relationships include issues of global structures, empowerment, participation, class, gender, origin, residency status, age, and position in

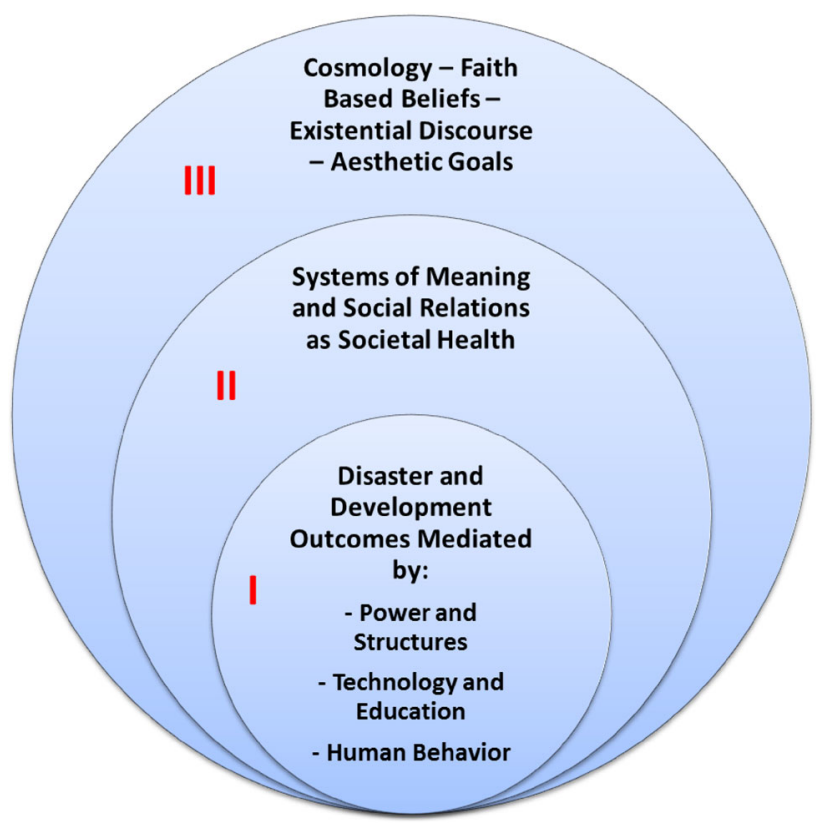

Fig. 1 Multileveled view of disaster and development

family structures and society. These shape the routes to disaster avoidance and mitigation, though inevitably also to responses and the relative impact of disasters on development trajectories.

Systems of meaning refer primarily to methodological needs to come up with a more satisfactory presentation of both structural and cultural sociologies of disaster and development, escaping overly simplistic and inappropriate divides between structure and culture. Structure and human agency in disaster and development approaches operate together. The basic perspective here is drawn from wider applicable ideas as, for example, reflected by Hays (1994) on "structure and agency and the sticky problem of culture." While it is not possible in practice to neatly separate issues across a structural-cultural divide, it is possible to derive more meaning in disaster and development work based on this more critical realist perspective if mindful of the crossover between structural and cultural factors.

Systems of meaning include beliefs, values of social groups, language, forms of knowledge, instinct, and variations in ways of being that influence disaster and development outcomes. Historically, disasters were considered acts of God. Science brought an explanation as to how physical environmental phenomena are part of natural systems of change. However, people have been left unsatisfied with both explanations, as neither acts of God nor applied science-based perspectives addressed the prevailing uncertainty about disasters sufficiently to adequately direct interventions. It is now commonplace to consider most major disasters as unnatural, being human induced, including through climate change, and a function 
of people being in the wrong place at the wrong time without adequate forms of protection. While the definition and parameters of disaster have remained contested, they increasingly emphasize social and economic drivers. Notions of development have been contested for many decades given a tension between equilibrium, growth, and social justice interpretations, and accentuate an urgency to identify sustainability transitions (Brauch 2019).

The milieu in both disaster and development studies has been accompanied by social constructivist interpretations of real and perceived hazards, risks, and disasters. This, however, can be seen as constraining where the needs of policy and practice are to interpret rapid, effectively, and justly for disaster impacts regularly experienced, extreme, and varied. Standards for practice such as, for example, through the Humanitarian Charter, ${ }^{3}$ responded in part by drawing on cultural values and learning for good practice. Examples in development work are the rights-based approaches referred to in the community-based action project examples referred to earlier in this article and those influenced by perspectives that draw variously from Western, Eastern, globalized, or otherwise sourced values that resurface with change. These are, however, as yet only loosely incorporated into more reflective disaster risk intervention assessments. Nonetheless, large parts of the sector remain influenced by world religions and variously oriented policymakers seeking to find transformations and impacts through change from within society as well as from without. Ultimately, systems of meaning, together with systems of social relations, guide human behavior for disaster and development.

It is suggested here that opening out the interpretations and opportunities presented by the disaster and development paradigm can facilitate changes needed for survival and a sustainable quality of life, not only for deeper thinking about the existing paradigm but also as a likely means to greater engagement. For example, peace building processes are tantamount to disaster risk reduction in the context of extremely disrupted or fragile states and regions. Social relations and systems of meaning, as considered in the context of combined conflict and disaster risk reduction, can involve common processes of early warning, rights, and resilience drawn from common values. ${ }^{4}$ This

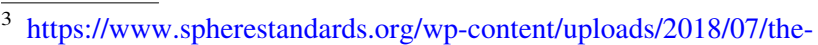
humanitarian-charter.pdf.

${ }^{4}$ Work in the field of conflict and disaster risk reduction was overlooked by much of the SFDRR process, but has been addressed concertedly in other fora. For example, the 2016 annual Dealing with Disasters (DwD) conference organized by Northumbria and Freetown Universities and the International Peace Research Association (IPRA) combined in Freetown, Sierra Leone, around the theme of "Agenda for Peace and Development; Conflict Prevention, Post-Conflict Transformation, and the Conflict, Disaster Risk and Sustainable Development Debate". This has led to the emergence of a revision of
}

would be a way forward for many areas experiencing conflicts and environmental hazards simultaneously or in tandem.

Beyond these systemic areas it is pertinent to also consider cosmologies, faith-based beliefs, existential discourses, or aesthetic goals that provide explanation or resolution to understanding human nature (Fig. 1, III). It is partly on this basis that more linear equations of risk reduction - such as those based on investment in sustainable development interventions (Collins 2009a, b), those that reduce the probability or magnitude of the disaster event (Smith 2001), or those that reduce hazard and vulnerability through improved capacity (Wisner et al. 2004) — can be expanded further for greater investment in motivation and engagement. This also requires greater emphasis on hope, evidence based or otherwise, as this stimulates action (Fig. 2). In such an approximation, evidence of risk reduction in action may be proportionate to some combination of certainty and hope that people draw upon or aspire to. This aligns with the consciousness implied by Fig. 1.

\section{Selected Action Research Fronts that Advance the Disaster and Development Paradigm}

Moving forward with disaster and development oriented DRR, based on the above analysis, suggests the need for ongoing development of the following.

\subsection{Building up Human Well-Being Earlier and More Urgently to Offset Negative Risks}

The SFDRR (UNISDR 2015a) has included as its fourth priority the earlier concept of "build back better" (Monday 2002). Though a desirable aim, this in itself generates a wider debate as to how such a process post-disaster is best to occur. In addition to tackling the merits of reconstruction and recovery-be these infrastructural, social, psychosocial, or other-a disaster and development perspective requires building up human well-being and capacity earlier and more effectively, so as to offset early the propensity for disaster impacts. For example, in analyzing transitions from a state of vulnerability to a state of well-being, Collins (2009a) indicated that this can be represented by overcoming combinations of biological susceptibility (malnourishment, exposure to hazardous environments and pathogens, lack of medicine and health care), mental impairment (lack of education, loss of skills, ideas and

Footnote 4 continued

Peace Ecology to encompass conflict and disaster risk reduction as an integrated concept. 
Evidence of Risk Reduction $\propto$ Evidence of Certainty x Evidence of Hope Economic, Cultural, and Biogeophysical Context

Fig. 2 Proportionate evidence of risk reduction in disaster and development

options, entrapment and dependency, cultural isolation), and insecurity (displacement, abuse, denied access to resources, lack of a voice or representation, conflict). While there is no panacea in mapping multiple types of contexts and human conditions, a transition from this integrated vulnerability to integrated well-being that offsets disaster impact would be characterized by:

- Health-nutrition, water, sanitation and clean air, pathogen avoidance and control, shelter, and energy, health care, and longevity;

- Resilience-coping, capacity, adaptability and creativity, social, economic, and cultural capital;

- Human security-rights, access to resources, representation, empowerment, absence of conflict.

The "build up early" approach is also implicit through calls for health and well-being centered disaster risk reduction. ${ }^{5}$ By way of operational specifics it is also relevant with this approach to emphasize that healthy groups (or societies) often impact on disaster risk in that they are comprised of people who are more able to:

- Get out of the way of disaster-including through aspirations to mobilize socially, economically, and physically, and able to also potentially help those around them;

- Offset risks with resilience to resurgent and emergent hazards, where resilience includes adaptive capacity as ability to improvise and overcome;

- Maintain aspirations for achieving greater survivability, sustainability, and human well-being;

- Access or apply decision-making roles.

A way in which this can occur is by learning to live better with inevitable uncertainties through adaptive processes; investing in the present in a precautionary and sustainable manner; and by dealing concertedly with any barriers there are to these processes (see Sects. 3.2, 3.3).

Proportionate hope resides in that unknowing - which includes the state of an inevitable lack of certainty — can be accompanied by significant vulnerability reduction through

\footnotetext{
5 In 2015 the Disaster and Development Network (DDN) ran the first international conference on "Health Centered Disaster Risk Reduction" as one of its Dealing with Disasters (DwD) series of events. This followed a concerted effort with the WHO and other agencies to make health more prominent in the SFDRR, since it had been all but left out of the previous HFA pre-2015. While there are many aspects to the role of health in the current framework, a central aspect has been to acknowledge health as both a prerequisite and an outcome of DRR, in an advancing disaster and development framing.
}

investment in transitions to sustainable well-being that would offset disaster threats. A virtuous spiral of risk sensitive development and disaster avoidance needs to be apparent both quantitatively and qualitatively in the lives of billions of people.

\subsection{Understanding the Means to Living with Uncertainty}

The second theme responds to the realist viewpoint that DRR decision making can be only as good as the capacity to predict and respond to environmental, economic, and social change. It can be argued that more complex intersections of environmental systems, power, and culture underlie the nature of risk reactions. Accentuated in relation to major human crises-be these climate-induced, development or conflict related-this systems understanding provides subjectively derived routes to DRR interventions that are dependent on everyday activities of all people who are ultimately at risk. As systems underlying risk reduction or its creation are better understood it becomes clearer how responsibility for risk management always resides somewhere. Moreover, risk as a function of uncertainty is by definition part non-experiential and nonevidence based (Collins 2015). This leads to an ascendant capacity to survive that requires actions driven also by moral, economic, or other imperatives rather than solely by risk assessment through measurement exercises.

It is pertinent to link again here to the "healthy disaster risk reduction" introduced in Sect. 3.1. Such people-centric approaches, whether health centered or otherwise (for example, oriented by education, planning, gender, conservation, or polycentric approaches) help identify that the right intervention in a complex system takes place in time and space. This, often peculiar, balance is dependent on the sentience of people who access, learn, implement, communicate, and cooperate with each other. Two aspects of living better with uncertainty are touched upon further in the following subsections; they are (1) realizing value in unknowing for some unknowns or unknowable aspects that lie in belief systems, the unanticipated, and the non-experiential; and (2) opportunities presented by individual and collective learning processes.

\subsubsection{Value in Unknowing and the Non-Experiential}

While uncertainty describes the conditions of unpredictability, unreliability, riskiness, chanciness, precariousness, or unsureness, a state of unknowing can be considered to be not knowing or aware, having a lack of awareness or knowledge. The two terms are not mutually exclusive or necessarily define an individual or group as deficient; unknowing might be simply an acceptance of the 
impossibility of knowing everything. Systems function where there may be gaps in knowledge as long as the requisite information gaps are usefully applied to problem solving. As such it is not necessary, and often not possible, to have achieved a fully evidenced-based prediction of an impending crisis before preventive actions could be taken on moral and ethical grounds.

The phenomenon of deciding on an acceptable and unacceptable level of risk, given gaps in information, can

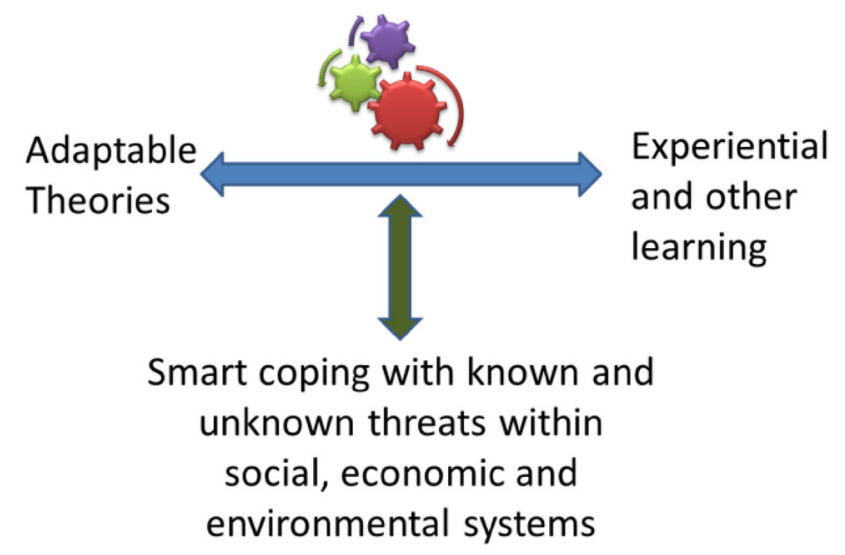

Fig. 3 Volatile and de facto understanding of disaster risk be pervasive in the field of emergency management and DRR, as it is in the insurance sector. A shortcoming is to miss the known, but ignored, such as for example, indigenous knowledge in DRR, which was commonly absent from the sector, although the "indigenous" theme gets written about (Mercer et al. 2010). What is being advanced here then is simply that: while aspirations of DRR to be evidence based and experiential should be upheld, this might be improved upon through consideration of all actions that might be taken without knowing everything. Adaptable theories and ever smarter coping with the known and the unknown (Fig. 3) are synonymous with smarter coping with known and unknown disaster risks. While the field needs to be, and often is, based on experience, in adapting and progressing theory to extend the paradigm, forms of non-experiential learning provide impetus (Collins 2015).

\subsubsection{Individual and Collective Learning in Disaster and Development}

Section 3.2.1 has argued that understanding disaster risk involves learning that is ongoing, reflective, and evaluative, and that this need not be entirely based on experience, not least since many complex emergencies are yet to come.
Fig. 4 Learning disaster risk and development individually and collectively

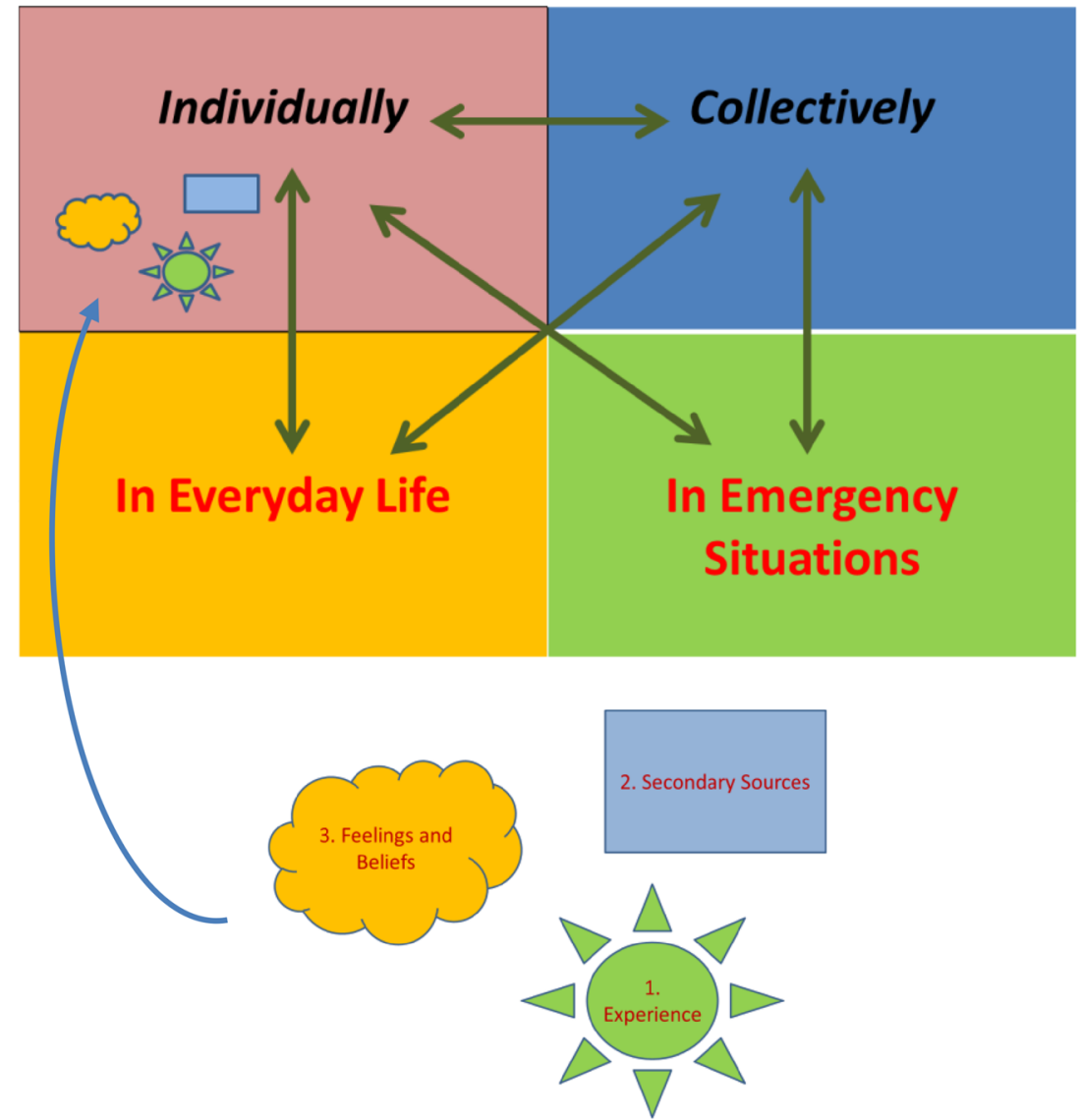


Table 1 Examples of barriers, transitioning, and outcomes for engagement in disaster risk reduction

\begin{tabular}{|c|c|c|}
\hline $\begin{array}{c}\text { Potential Barriers } \\
\text { (Boundaries) }\end{array}$ & $\begin{array}{c}\text { Nature of } \\
\text { Transitioning }\end{array}$ & \multicolumn{1}{|c|}{ Outcomes } \\
\hline Rualifiers/quantifiers & Processes are: & Consistent with, \\
Risk perceptions & Risky & advanced forward or \\
Insecure/secure & Tranite/Infinite & backwards from previous \\
systems & Self-regulating & state \\
Communication & Balanced/Uneven & Resilient/Hardened \\
Cultural specificity & Accelerated/Slowed & Secure \\
Social economy & Through: & Vulnerable \\
Market forces & Financial investment & Fragile \\
Knowledge & Mobility & Homplex \\
Trust & Reflective practice & Capable \\
Habitat/Places & Educational advancement & Sustainable \\
Values & Creative engagement & Placed \\
Uncertain behavior & Asset exchange & Ethical \\
\hline
\end{tabular}

Learning from beyond what is personally experienced occurs through an array of secondary sources, such as records of the emergency services, relief and development agencies, libraries, and other written or verbal sources, whether formally documented or not. The combination of experiential learning of an individual is however supplemented by feelings and beliefs. The notion of a gut feeling, instinct, or intuition for actions taken in emergencies is well talked about within the sector. However, a problem is that the experiences, interpretations of secondary sources, and feelings and beliefs of individuals regarding disaster prevention and preparedness may or may not be heard or accepted by others around them. It is reasonable to propose therefore that where a plural interpretation of learning might be more collective, a powerful level of group behavior transitioning for everyday life and emergency situations might be harnessed (Fig. 4). Success with what has become widely known as community-based disaster risk reduction and community-based development programming, may be understood further along these lines, although here the meaning refers specifically to peoplecentered approaches; there are ambiguities or misrepresentations of what is "community" in this field of work (Titz et al. 2018).

\subsection{Addressing Barriers and Transitions in Disaster Risk Reduction and Sustainable Development}

Much of the analysis in this article confirms the importance of understanding risk in terms of systems of disaster and development interdependencies that are key to implementing DRR. Solutions for DRR frequently present as wider development, motivational, and interpretational issues paramount to successful everyday life. It is as though a significant part of what is required is to do more with what is already known and actionable, and to ask what are the obstacles to otherwise readily available solutions. To this end, the third of the action research fronts presented here focuses on the need to better understand the sets of barriers there are for more effective DRR and to ask what transitioning is needed for individuals, institutions, and groups to overcome these.

By way of an outline analysis on this point, Table 1 presents some of the types of barriers there are in disaster and development work, and the nature of transitioning that might take place towards different types of outcomes. This is not intended as a definitive list, which varies in place, time, and in relation to different types of people. However, in itself it shows a form of analytics that could be considered more in-depth to advance the way that human engagement in DRR is interpreted, while suggesting what might be overcome or adapted in everyday life and the consequent outcomes.

For example, using Table 1 as a thought enabler and considering the case of wanting to achieve advances in responses to early warnings, communication is often considered a barrier; people may hear a warning but not react because they either misinterpret what the warning requires them to do, do not believe the warning or its severity, are unable to do anything in response to the warning, or may be of a risky disposition and choose to take a chance. The barriers to transition need to be removed, either incrementally or at once, for greater effectiveness. They include in this instance, for example, issues of trust and perception. 
Depending on context, potential combinations of other characteristic boundaries listed in the left column would also apply. Characteristic transitioning might be considered to include features listed in the middle column. Potential outcomes of transitioning are indicated in the right column. However, a way in which to carry out the analysis is to start with the outcome and to work back in considering the forms of transition across particular types of barriers. It is not an exacting process, but if the basic principle of moving forward the disaster and development paradigm for DRR by removing barriers is considered recurrently, this may prove to be cost-effective and enable impactful contributions to addressing critical forthcoming threats. The concept here is that DRR will better operate when free of both the externally imposed and any self-inflicted forms of harmful risk inducing constraint.

\section{Conclusion}

This article calls for advancement of the disaster and development paradigm, particularly with respect to its ongoing contribution to DRR. Reviewing of the current paradigm already confirms a need to emphasize the evolution of maneuverable ideas in finding intellectual and applied ways out of impasse for the sake of future survivability. Some progress in the policy environment is evident but it is often the case that disaster risk reduction decision making is only as good as the capacity to understand and respond to environmental, economic, and social change. Less progress has been made in addressing complex intersections of environmental systems, power, and cultures that underlie emergent understanding of the nature of risk reactions and active engagement.

As ways forward may become more accessible than hitherto encountered within this sector, aspirations to build up quality of life in a risk sensitive manner has to be enabled further alongside any advance of the paradigm. Health and well-being aspects present a readily accessible and transformative way to advance the actuality of a fully people-centered approach. We can note in this context also that hope resides in that unknowing can be accompanied by vulnerability reduction and investments in sustainable development that would offset both known and unknown disaster threats. Risk as a function of uncertainty is part non-experiential and non-evidence based. More progress could therefore also be harnessed by greater use of disaster and development collective awareness and engagement. Recognizing and acting upon the barriers to people taking control of DRR for themselves within their own lives is very much part of the disaster and development paradigm. Barrier removal for transitioning to future security, peace, and well-being, however, also requires appropriate political and economic contexts, and will require new technological breakthroughs that reduce the creation of hazards, risks, and disasters in society. An ascendant capacity to survive therefore requires actions driven by combinations of moral imperatives and plenty of highly motivated people.

Acknowledgements The author would like to thank the reviewers for useful comments on this paper. The paper is based on a presentation given to the IASS-IDRiM Workshop on Risk Governance for Natural Disasters-Extending Integrated Disaster Risk Management to Sustainable Communities, Institute for Advanced Sustainability Studies (IASS), Potsdam, 29 August 2017. Thanks to Norio Okada (IDRiM) and Ortwin Renn (IASS) for their hosting of this event.

Open Access This article is distributed under the terms of the Creative Commons Attribution 4.0 International License (http://crea tivecommons.org/licenses/by/4.0/), which permits unrestricted use, distribution, and reproduction in any medium, provided you give appropriate credit to the original author(s) and the source, provide a link to the Creative Commons license, and indicate if changes were made.

\section{References}

Bankhoff, G., G. Frerks, and D. Hilhorst (eds.). 2004. Mapping vulnerability: Disasters, development and people. London: Earthscan.

Blaikie, P., T. Cannon, I. Davis, and B. Wisner. 1994. At risk, 1st edn. London: Routledge.

Brauch, H.G. 2019. Sustainable peace through sustainability transition as transformative science: A peace ecology perspective in the Anthropocene. In Climate change, disasters, sustainability transition and peace in the Anthropocene, ed. H.G. Brauch, U.O. Spring, A.E. Collins, and S.E.S. Oswald, 175-234. Switzerland: Springer Nature.

Cannon, T. 1994. Vulnerability analysis and the explanation of "natural" disasters. In Disasters, development and the environment, ed. A. Varley, 13-30. Chichester: John Wiley.

Collins, A.E. 2009a. Disaster and development. London: Routledge.

Collins, A.E. 2009b. Early warning: The people centred approach to early warning systems and the "last mile". In World disaster report 2009, ed. L. Knight, 39-68. Geneva: International Federation of Red Cross and Red Crescent Societies (IFRC).

Collins, A.E. 2013. Linking disaster and development: Further challenges and opportunities. Environmental Hazards 12(1): $1-4$.

Collins, A.E. 2015. Beyond experiential learning in disaster and development communication. In Learning and calamities: Practices, interpretations, patterns, ed. H. Egner, M. Schorch, and M. Voss, 56-76. London: Routledge.

Collins, A.E. 2019. Advancing disaster and conflict risk reduction. In Climate change, disasters, sustainability transition and peace in the Anthropocene, ed. H.G. Brauch, U.O. Spring, A.E. Collins, and S.E.S. Oswald, 7-26. Switzerland: Springer Nature.

Collins, A.E., S. Jones, B.S. Manyena, and J. Jayawickrama (eds.). 2015. Hazards, risks and disasters in society. Oxford: Elsevier.

Collins, A.E., M.E. Lucas, M.S. Islam, and L.E. Williams. 2006. Socio-economic and environmental origins of cholera epidemics in Mozambique: Guidelines for tackling uncertainty in infectious disease prevention and control. International Journal of Environmental Studies 63(5): 537-549. 
Cuny, F. 1983. Disaster and development. Oxford: Oxford University Press.

Cutter, S.L., B.J. Boruff, and W.L. Shirley. 2003. Social vulnerability to environmental hazards. Social Science Quarterly 84(2): 242-261.

De Waal, A. 1997. Famine crimes: Politics \& the disaster relief industry in Africa. Bloomington, IN: Indiana University Press.

Enarson, E., and M. Fordham. 2011. From women's needs to women's rights in disasters. Environmental Hazards 3(3): 133-136.

Gaillard, J.C. 2010. Vulnerability, capacity and resilience: Perspectives for climate and development policy. Journal of International Development 22(2): 218-232.

Godschalk, D.R., T. Beatley, P. Berke, D.J. Brower, E.J. Kaiser, C.C. Bohl, and R.M. Goebel. 1999. Natural hazard mitigation: Recasting disaster policy and planning. Washington, DC: Island Press.

Hays, S. 1994. Structure and agency and the sticky problem of culture. Sociological Theory 12(1): 57-72.

Hewitt, K. 1995. Sustainable disaster? Perspectives and powers in the discourse of calamity. In Power of development, ed. J. Crush, 115-128. London: Routledge.

Hewitt, K. 1997. Regions of risk: A geographical introduction to disasters. London: Routledge.

IFRC (International Federation of Red Cross and Red Crescent Societies). 2007. World disaster report 2007-focus on discrimination. https://media.ifrc.org/ifrc/document/world-disasters-rep ort-2007-focus-discrimination/. Accessed 1 Jul 2018.

Jones, S., K. Aryal, and A.E. Collins. 2013. Local-level governance of risk and resilience in Nepal. Disasters 37(3): 442-467.

Jones, S., K. Oven, B.S. Manyena, and K. Aryal. 2014. Governance struggles and policy processes in disaster risk reduction: A case study from Nepal. Geoforum 57: 78-90.

Krüger, F., G. Bankoff, T. Cannon, B. Orlowski, and L.F. Schipper (eds.). 2015. Cultures and disasters: Understanding cultural framings in disaster risk reduction. London: Routledge.

Lewis, J. 1999. Development in disaster-prone places: Studies of vulnerability. London: Intermediate Technology Publications.

Lewis, J. 2012. The good, the bad and the ugly: Disaster Risk Reduction (DRR) versus Disaster Risk Creation (DRC). Plos Currents. https://doi.org/10.1371/4f8d4eaec6af8.

Lewis, J. 2014. The susceptibility of the vulnerable: Some realities reassessed. Disaster Prevention and Management 23(1): 2-11.

Manyena, S.B., A.E. Collins, F. Mudimba, and D. Mudimba. 2012. "Are you serious to ask me about who owns wildlife?" Politics of autonomy over wildlife resources in the Zambezi Valley, Zimbabwe. Forum for Development Studies 40(1): 87-109.

Manyena, S.B., A.E. Collins, F. Mudimba, and D. Mudimba. 2016. Reducing marginalization of fishermen through participatory action research in the Zambezi Valley, Zimbabwe. International Journal of African Development 3(2): 5-22.

Mercer, J., I. Kelman, L. Taranis, and S. Suchet-Pearson. 2010. Framework for integrating indigenous and scientific knowledge for disaster risk reduction. Disasters 34(1): 214-239.
Middleton, N., and P. O'Keefe. 1998. Disaster and development: The politics of humanitarian aid. London: Pluto.

Monday, J.L. 2002. Building back better: Creating a sustainable community after disaster. Natural Hazards Informer 3: 1-11.

Pelling, M., and K. Dill. 2010. Disaster politics: Tipping points for change in the adaptation of sociopolitical regimes. Progress in Human Geography 34(1): 21-37.

Perry, R.W., and E.L. Quarantelli. 2005. What is a disaster? New answers to old questions. Bloomington, IN: Xlibris.

Quarantelli, E.L. 1998. What is a disaster? Perspectives on the question. London: Routledge.

Smith, K. 2001. Environmental hazards: Assessing risk and reducing disaster, 3rd edn. London: Routledge.

Titz, A., T. Cannon, and F. Krüger. 2018. Uncovering "community": Challenging an elusive concept in development and disaster related work. Societies 8(3): 1-28.

Tobin, G.A., and B.E. Montz. 1997. Natural hazards: Explanation and integration. London: Guildford Press.

UNISDR (United Nations International Strategy for Disaster Reduction). 2009. 2009 global assessment report on disaster risk reduction: Risk and poverty in a changing climate. Geneva, Switzerland: United Nations.

UNISDR (United Nations International Strategy for Disaster Reduction). 2011a. Risk returns. London: Tudor Rose.

UNISDR (United Nations International Strategy for Disaster Reduction). 2011b. 2011 global assessment report on disaster risk reduction: Revealing risk, redefining development. Geneva, Switzerland: United Nations.

UNISDR (United Nations International Strategy for Disaster Reduction). 2013. 2013 global assessment report on disaster risk reduction-From shared risk to shared value: The business case for disaster risk reduction. Geneva, Switzerland: United Nations.

UNISDR (United Nations International Strategy for Disaster Reduction). 2015a. Sendai framework for disaster risk reduction 20152030. Geneva, Switzerland: UNISDR.

UNISDR (United Nations International Strategy for Disaster Reduction). 2015b. 2015 global assessment report on disaster risk reduction-Making development sustainable: The future of disaster risk management. Geneva, Switzerland: United Nations.

UNISDR (United Nations International Strategy for Disaster Reduction). 2016a. Implementing the Sendai framework to achieve the sustainable development goals. Geneva, Switzerland: UNISDR.

UNISDR (United Nations International Strategy for Disaster Reduction). 2016b. Report of the open-ended intergovernmental expert working group on indicators and terminology relating to disaster risk reduction. Geneva, Switzerland: UNISDR and UNGA.

Williams, L., A.E. Collins, A. Bauaze, and R. Edgeworth. 2010. The role of risk perception in reducing cholera vulnerability. Risk Management 12(3): 163-184.

Wisner, B., P. Blaikie, T. Cannon, and I. Davis. 2004. At risk: Natural hazards, people's vulnerability and disasters, 2nd edn. London: Routledge.

WHS (World Humanitarian Summit) (ed.). 2016. Together we stand. London: Tudor Rose/Gomer Press. 